\title{
Micro-flow synthesis and structural analysis of sterically crowded diimine ligands with five aryl rings
}

\author{
Shinichiro Fuse ${ }^{* 1}$, Nobutake Tanabe ${ }^{1}$, Akio Tannna ${ }^{2}$, Yohei Konishi ${ }^{2}$ \\ and Takashi Takahashi ${ }^{1}$
}

\section{Full Research Paper}

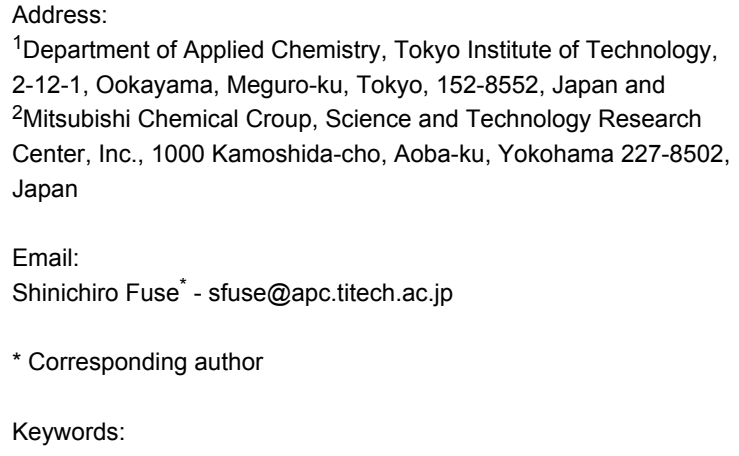

\begin{abstract}
Sterically crowded diimine ligands with five aryl rings were prepared in one step in good yields using a micro-flow technique. X-ray crystallographic analysis revealed the detailed structure of the bulky ligands. The nickel complexes prepared from the ligands exerted high polymerization activity in the ethylene homopolymerization and copolymerization of ethylene with polar monomers.
\end{abstract}

\section{Introduction}

The design of a ligand is a key step in the development of new catalysts because the ligand framework influences the reactivity of the metal center. That is why sterically crowded and neutral-chelating diimine ligands have garnered a great deal of attention [1-17]. In recent years, $N$-aryl 1,3,5-triazapenta-1,4dienes $\mathbf{1}$ and $\mathbf{2}$ have been reported, and they are useful with late transition metal olefin-polymerization catalysts $[18,19]$, and for the stabilization and isolation of reactive metal species [20,21] In 1997, Murillo and coworkers reported the synthesis of a neutral, and bulky chelating ligand $\mathbf{1}$, and its use in the forma- tion of a Co complex (Figure 1) [22]. Stephan and coworkers reported the synthesis of a bulkier chelating ligand $\mathbf{2 a}$, and its use in the formation of various metal complexes [20,21]. Rojas and coworkers reported the synthesis of a series of bulky chelating ligands $\mathbf{2} \mathbf{b}-\mathbf{g}$, and detailed their use in the preparation of ethylene polymerization catalysts $[18,19]$. We became curious about the structure and function of 1,2,3,4,5-pentaaryl1,3,5-triazapenta-1,4-diene ligand $\mathbf{3}$, which is sterically more hindered, because there are as many as five aryl rings that can provide further opportunities to change and tune the steric and 


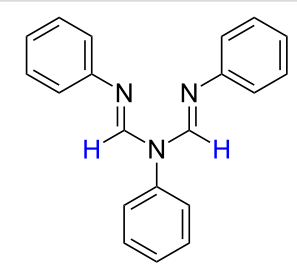

1

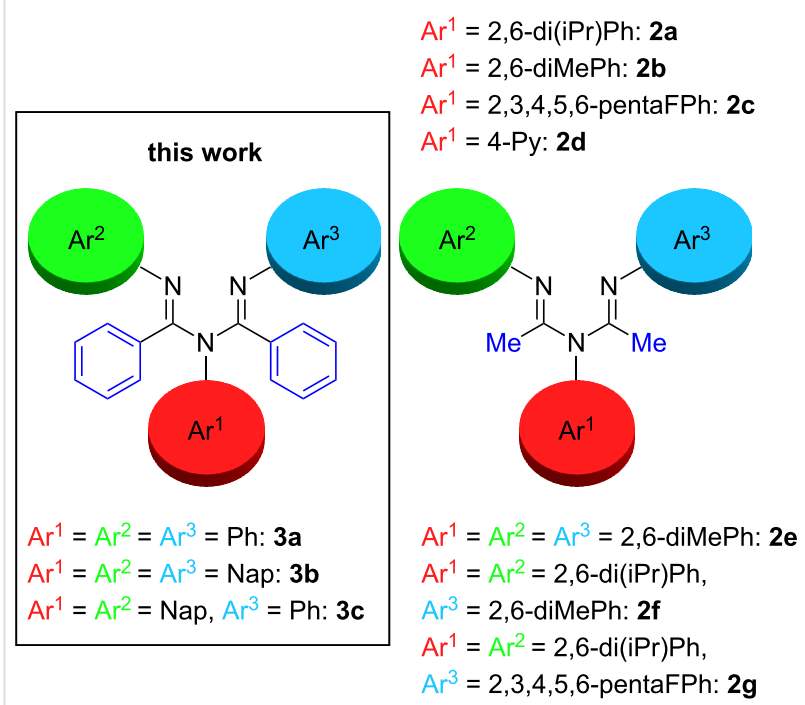

Figure 1: Sterically crowded, and neutral chelating diimine ligands.

electrical environments of the ligands [23,24]. However, as far as we could ascertain, this has been reported only once [25]. In this pioneering work, 1,2,3,4,5-pentaphenyl-1,3,5-triazapenta1,4-diene ligand 3a was prepared, but the report included neither the complexation nor a detailed structural study.

Herein, we report an efficient micro-flow synthesis and structural analysis of sterically crowded 1,2,3,4,5-pentaaryl-1,3,5triazapenta-1,4-diene ligands $\mathbf{3 b}$ and $\mathbf{3 c}$, and their use in the copolymerization of ethylene and polar monomers. According to the previous report, 1,2,3,4,5-pentaphenyl-1,3,5-triazapenta-1,4diene ligand 3a was prepared by the reaction of $N, N^{\prime}$-diphenyl benzamidine and $N$-phenylbenzimidochloride in benzene in 13 days [25]. In the present study, we intended to prepare these ligands from readily available materials in only one step $[18,21]$.

\section{Results and Discussion}

Two equivalents of $N$-naphthylbenzimidochloride (4) was reacted with one equivalent of naphthylamine (5) in $\mathrm{CH}_{2} \mathrm{Cl}_{2}$ in the presence of DIEA ( $N, N$-diisopropylethylamine) at room temperature (Scheme 1). The reaction proceeded smoothly, and consumption of naphthylamine was confirmed by TLC analysis within $10 \mathrm{~min}$. After an aqueous workup, the desired product $\mathbf{3 b}$ was obtained in a moderate yield (44\%) with the concomitant generation of naphthylamine (5) and amide 8. Reportedly, 3a can form an $\mathrm{HCl}$ adduct, and the adduct decomposes to the corresponding amidine and imidochloride [25]. It is conceivable that $\mathbf{3 b}$ overreacted with DIEA $\cdot \mathrm{HCl}$ to afford $\mathbf{6}$, or $\mathbf{4}$ and $\mathbf{7}$ in the reaction mixture and that $\mathbf{5}$ and $\mathbf{8}$ were generated from the hydrolysis of these compounds under aqueous workup conditions. We decided to use a micro-flow reactor in order to suppress the overreaction $[26,27]$ because the micro-flow technique [28-35] enables the precise control of reaction time and temperature. The micro-flow system was made from simple and inexpensive laboratory instruments (syringes, syringe pumps, water bath, T-shape mixer, standard tubing and fittings), as shown in Figure 2. The T-shape mixer was made of stainless steel and immersed in a water bath $\left(20^{\circ} \mathrm{C}\right)$. A solution of 4 $(0.1 \mathrm{M})$ in $\mathrm{CH}_{2} \mathrm{Cl}_{2}$, a solution of aryl amine 5 or $9(0.1 \mathrm{M})$, and DIEA $(0.7 \mathrm{M})$ in $\mathrm{CH}_{2} \mathrm{Cl}_{2}$ were introduced using syringe pumps at the indicated flow rates. The reaction was quenched by pouring the mixture into a saturated aqueous solution of $\mathrm{NH}_{4} \mathrm{Cl}$ in $\mathrm{CH}_{2} \mathrm{Cl}_{2}$. After an aqueous workup, the products $\mathbf{3 b}$ and $\mathbf{3 c}$ were purified by silica gel chromatography. Reaction time was controlled by changing the flow rates.

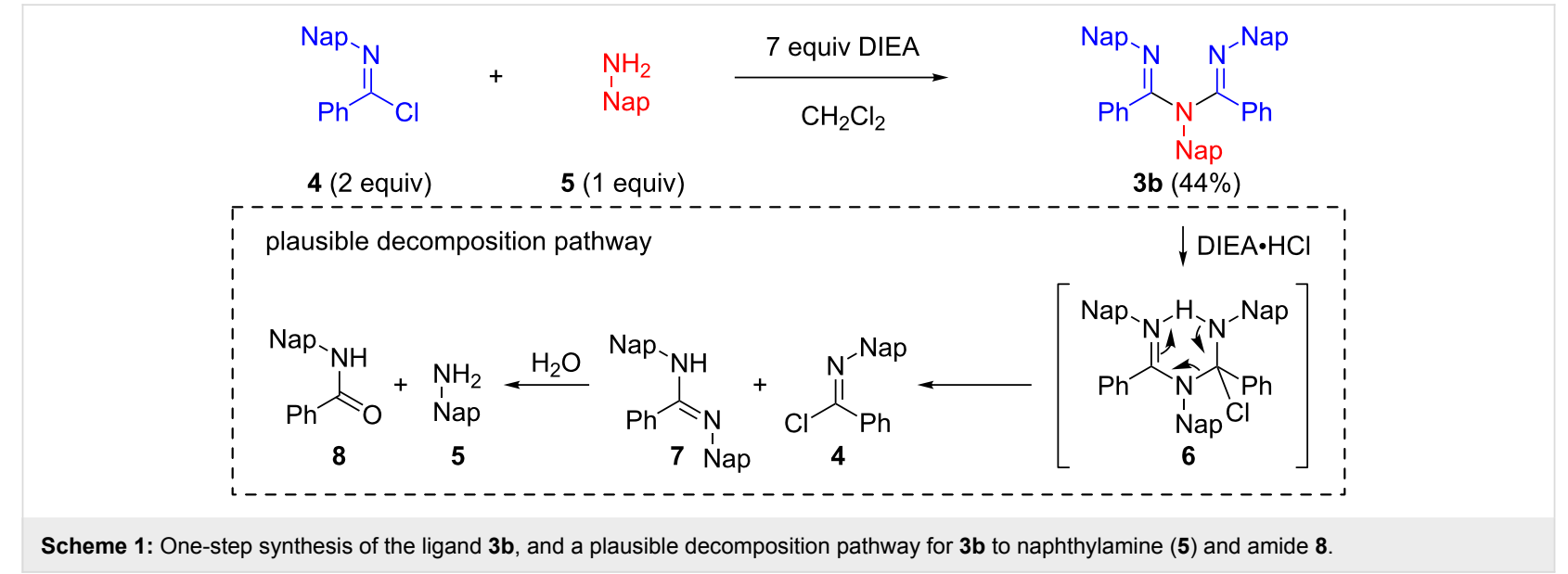




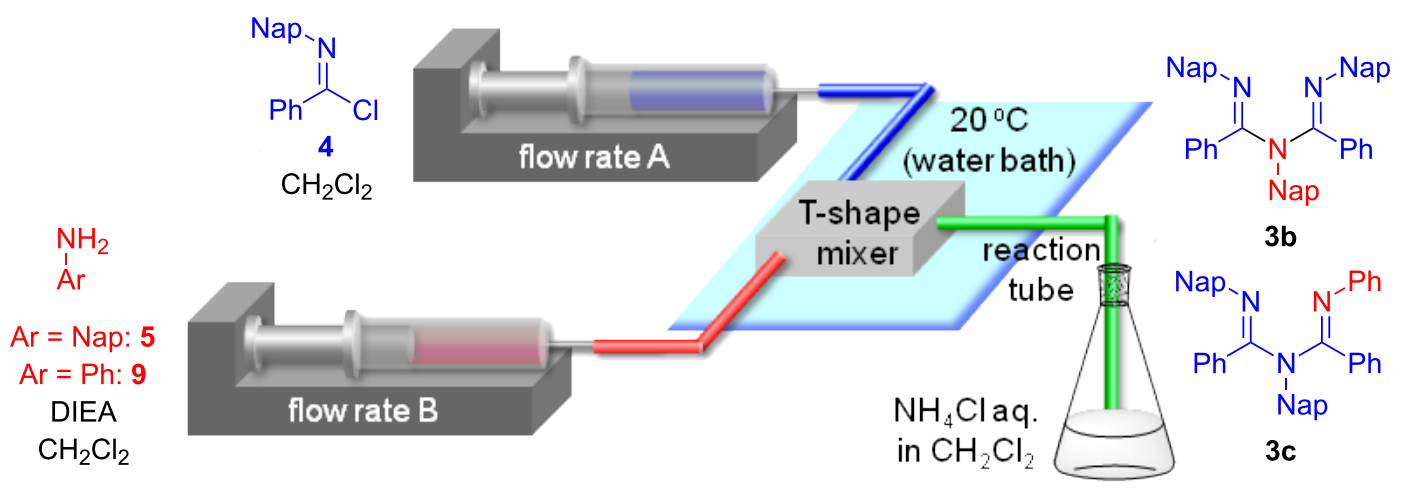

Figure 2: Micro-flow synthesis of the ligands $\mathbf{3 b}$ and $\mathbf{3 c}$.

As expected, the yield of $\mathbf{3 b}$ was improved by reducing the reaction time (Table 1, entries 1-4). The highest yield was observed for a reaction time of $38 \mathrm{~s}$ (Table 1, entry 4). A further shortening of the reaction time resulted in a reduction in the yield because of substrate recovery (Table 1 , entry 5 ).

\begin{tabular}{|c|c|c|c|c|c|}
\hline entry & $\begin{array}{c}\text { flow rate } A \\
{[\mu L / m i n]}\end{array}$ & $\begin{array}{c}\text { flow rate B } \\
{[\mu \mathrm{L} / \mathrm{min}]}\end{array}$ & $\begin{array}{c}\text { time } \\
{[\mathrm{s}]}\end{array}$ & $\mathrm{Ar}-\mathrm{NH}_{2}$ & $\begin{array}{c}\text { yield }^{a} \\
{[\%]}\end{array}$ \\
\hline $1^{b}$ & 54 & 27 & 300 & 5 & 65 \\
\hline $2^{b}$ & 106 & 53 & 150 & 5 & 72 \\
\hline $3^{b}$ & 214 & 107 & 75 & 5 & 75 \\
\hline $4^{b}$ & 426 & 213 & 38 & 5 & 84 \\
\hline $5^{b}$ & 854 & 427 & 19 & 5 & 66 \\
\hline $6^{c}$ & 214 & 107 & 50 & 9 & 55 \\
\hline $7^{c}$ & 426 & 213 & 25 & 9 & 69 \\
\hline $8^{c}$ & 854 & 427 & 13 & 9 & 66 \\
\hline
\end{tabular}

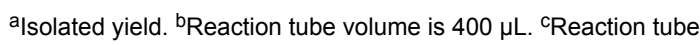
volume is $266 \mu \mathrm{L}$.

The structure of the ligand $\mathbf{3 b}$ was unambiguously determined by ${ }^{1} \mathrm{H}$ NMR, ${ }^{13} \mathrm{C}$ NMR, IR, HRMS and X-ray crystallographic analysis [36] (Figure 3). The ORTEP structure of $\mathbf{3 b}$ showed that in the solid state the ligand adopts a non-planar arrangement similar to the previously reported ligands $\mathbf{2 a}-\mathbf{c}$, and $\mathbf{2 e -} \mathbf{- g}$ $[18,19,21]$. In ligand $\mathbf{3 b}, \mathrm{N}(1)$ and $\mathrm{N}(2)$ nearly occupied a common plane with $\mathrm{C}(1)$ and $\mathrm{C}(2)$, while $\mathrm{N}(3)$ was twisted out of this plane and was nearly perpendicular. The bond lengths for imines $\mathrm{C}(1)-\mathrm{N}(1)$ and $\mathrm{C}(2)-\mathrm{N}(3)$ were 1.273(4) and $1.278(4) \AA$, respectively, while the bond lengths for amines $\mathrm{C}(1)-\mathrm{N}(2)$ and $\mathrm{C}(2)-\mathrm{N}(2)$ were $1.420(4)$ and 1.421(4) $\AA$, respectively. Reportedly, the two amine bond lengths were different in the case of ligands, $\mathbf{2 a}, \mathbf{2 b}, \mathbf{2 e}, \mathbf{2 f}$, and $\mathbf{2 g}$ for which $\mathrm{N}=\mathrm{C}-\mathrm{N}-\mathrm{C}=\mathrm{N}$ was not in a common plane. On the other hand, the two amine bond lengths were nearly identical in the case of ligand $2 \mathbf{c}$ where $\mathrm{N}=\mathrm{C}-\mathrm{N}-\mathrm{C}=\mathrm{N}$ was in a common plane. Interestingly, in the case of ligand $\mathbf{3 b}$, the bond lengths of the two amines, $\mathrm{C}(1)-\mathrm{N}(2)$ and $\mathrm{C}(2)-\mathrm{N}(2)$ were nearly identical, although $\mathrm{N}=\mathrm{C}-\mathrm{N}-\mathrm{C}=\mathrm{N}$ was not in a common plane.

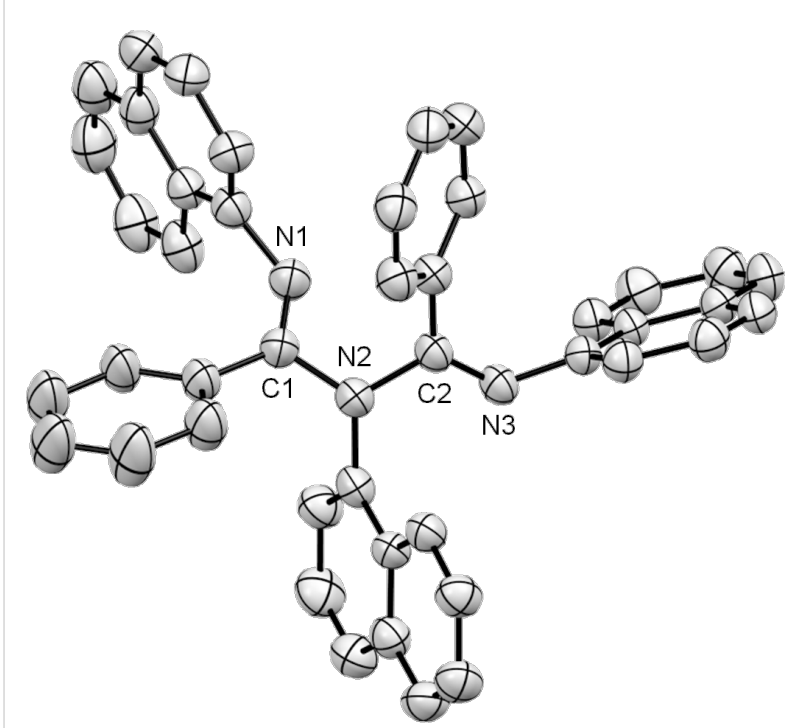

Figure 3: ORTEP drawing of 3b. Thermal ellipsoids are set at $35 \%$ probability level. Hydrogen atoms are omitted for clarity. Selected bond lengths $[\AA]$ and angles $\left[^{\circ}\right]$ are as follows: $\mathrm{C}(1)-\mathrm{N}(1) 1.273(4)$, $\mathrm{C}(1)-\mathrm{N}(2) 1.420(4), \mathrm{C}(2)-\mathrm{N}(2) 1.421(4), \mathrm{C}(2)-\mathrm{N}(3) 1.278(4)$, $\mathrm{N}(1)-\mathrm{C}(1)-\mathrm{N}(2)$ 115.3(3), C(1)-N(2)-C(2) 117.0(3), N(2)-C(2)-N(3) 117.8(3).

The asymmetric ligand 3c was obtained by the coupling of $N$-naphthylbenzimidochloride (4) with aniline (9). The product was obtained in a satisfactory yield (69\%) under the conditions of entry 7 (25 s), as shown in Table 1 . We speculated that the slightly lower yield of $\mathbf{3 c}$ compared to $\mathbf{3 b}$ came from the instability of $\mathbf{3 c}$ during purification process. The compound $\mathbf{3 c}$ was less stable than $\mathbf{3 b}$. Rojas et al. reported that the regioselectivity in the nucleophilic addition of an amidine to an 


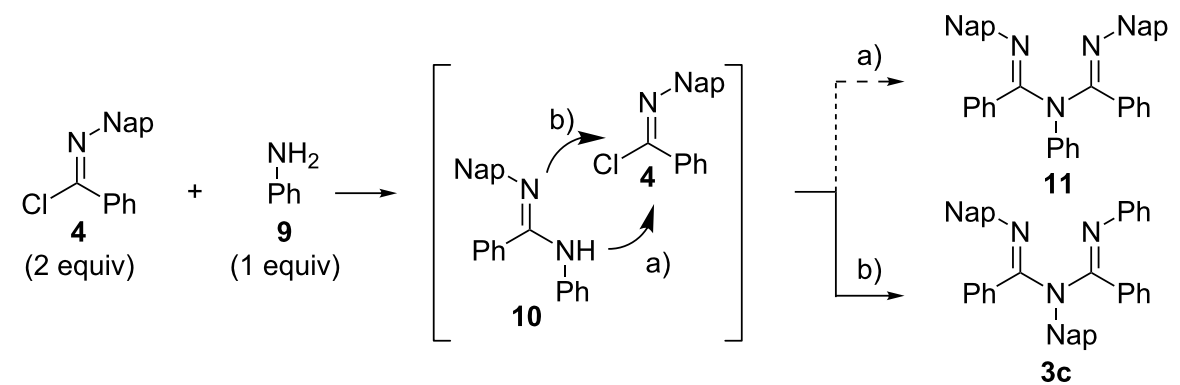

Scheme 2: Synthesis of the ligand 3c through the coupling of $\mathbf{4}$ and $\mathbf{9 .}$

imidochloride depends on the employed reaction conditions, in particular, the order of addition and the base selection [37] and the symmetric ligands were obtained through the coupling of $N$-2,6-di(iPr)-phenylbenzimidochloride with aryl amines in the presence of $\mathrm{Et}_{3} \mathrm{~N}$ in toluene [18,19]. Interestingly, in our case, only the asymmetric ligand $\mathbf{3 c}$ was obtained, although similar reaction conditions were employed (Scheme 2). The result showed that the nucleophilic addition of amidine $\mathbf{1 0}$ occurred from the sterically more hindered nitrogen atom (path b).

The structure of the asymmetric ligand $\mathbf{3 c}$ was unambiguously determined by ${ }^{1} \mathrm{H}$ NMR, IR, HRMS and X-ray crystallographic analysis (Figure 4). The ORTEP structure of $\mathbf{3 c}$ showed that in the solid state, the ligand adopted a non-planar arrangement similar to that of $\mathbf{3 b}$. In the ligand $\mathbf{3 c}, \mathrm{N}(1)$ and $\mathrm{N}(2)$ occupied a plane that was near that of $\mathrm{C}(1)$ and $\mathrm{C}(2)$, while $\mathrm{N}(3)$ was twisted out of this plane and was almost perpendicular. The

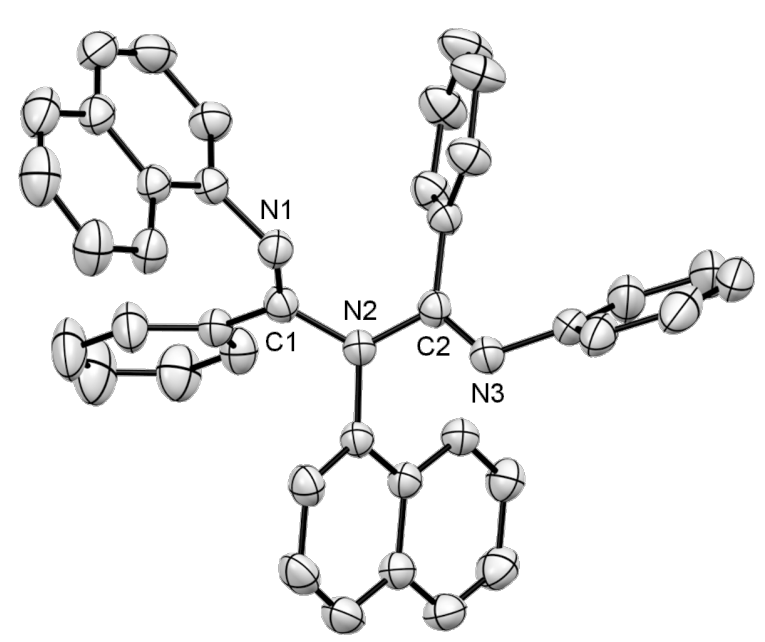

Figure 4: ORTEP drawing of 3c. Thermal ellipsoids are set at $35 \%$ probability level. Hydrogen atoms are omitted for clarity. Selected bond lengths $[\AA]$ and angles $\left[{ }^{\circ}\right]$ are as follows: $\mathrm{C}(1)-\mathrm{N}(1) 1.269(3)$, $\mathrm{C}(1)-\mathrm{N}(2) 1.413(3), \mathrm{C}(2)-\mathrm{N}(2) 1.411(3), \mathrm{C}(2)-\mathrm{N}(3)$ 1.274(3), $\mathrm{N}(1)-\mathrm{C}(1)-\mathrm{N}(2) 116.5(2), \mathrm{C}(1)-\mathrm{N}(2)-\mathrm{C}(2) 119.1(2), \mathrm{N}(2)-\mathrm{C}(2)-\mathrm{N}(3)$ $117.4(2)$. bond lengths for imines $\mathrm{C}(1)-\mathrm{N}(1)$ and $\mathrm{C}(2)-\mathrm{N}(3)$ were $1.269(3)$ and 1.274(3) $\AA$, respectively, while the bond lengths for amines $\mathrm{C}(1)-\mathrm{N}(2)$ and $\mathrm{C}(2)-\mathrm{N}(2)$ were $1.413(3)$ and 1.411(3) A, respectively. The bond lengths for amines $\mathrm{C}(1)-\mathrm{N}(2)$ and $\mathrm{C}(2)-\mathrm{N}(2)$ were nearly identical, although $\mathrm{N}=\mathrm{C}-\mathrm{N}-\mathrm{C}=\mathrm{N}$ was not in a common plane. These features were similar to that of $\mathbf{3 b}$.

A complexation of the synthesized ligands $\mathbf{3 b}$ and $\mathbf{3} \mathbf{c}$ with nickel(II) was performed (Scheme 3 ) in accordance with a reported procedure [38]. An equimolar amount of $\mathrm{NiBr}_{2}(\mathrm{dme})$ (dme $=1,2$-dimethoxyethane) and the synthesized ligands were mixed in $\mathrm{CH}_{2} \mathrm{Cl}_{2}$ and stirred for $4 \mathrm{~h}$ at room temperature. Free ligands $\mathbf{3 b}$ or $\mathbf{3} \mathbf{c}$ were not observed by ${ }^{1} \mathrm{H}$ NMR analysis of the obtained crude mixtures. NMR characterization of the complexes 12 and $\mathbf{1 3}$ was poor due to the paramagnetic nature of the pseudo-tetrahedral nickel centers. In the case of $\mathbf{1 2}$, green needle-like crystals suitable for X-ray crystallographic analysis were obtained (Figure 5). The molecular structure confirmed the formation of a six-membered chelate ring by the ligand in a $N, N$ binding mode to the nickel dibromide. All the aryl rings were almost perpendicular to the chelate plane probably due to the strong steric repulsions among the aryl rings. The tetrahedral geometry around nickel was distorted similar to the previously reported nickel complexes of $\mathbf{2 b}, \mathbf{2 f}$ and $\mathbf{2 g}$ [18,19]. For example, $\operatorname{Br}(1)$ was almost perpendicular to the plane of the metal-containing ring. This can be observed in the corresponding angle $\mathrm{N}(1)-\mathrm{Ni}(1)-\mathrm{Br}(1) 102.2(3)^{\circ}$, while the angle of $\mathrm{N}(1)-\mathrm{Ni}(1)-\mathrm{Br}(2)$ was $120.9(3)^{\circ}$. The $\mathrm{C}(1)-\mathrm{N}(1), \mathrm{C}(2)-\mathrm{N}(3)$,

$$
\begin{gathered}
\mathrm{R}=\mathrm{Nap}: \mathbf{1 2} \\
\mathrm{R}=\mathrm{Ph}: \mathbf{1 3}
\end{gathered}
$$

Scheme 3: Complexation of the ligands $\mathbf{3 b}$ and $\mathbf{3 c}$ with $\mathrm{NiBr}_{2}(\mathrm{dme})$ 


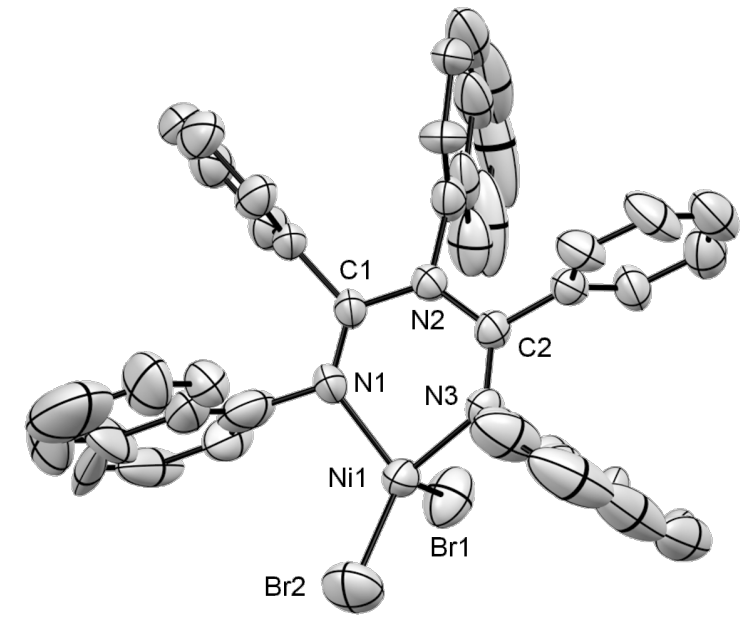

Figure 5: ORTEP drawing of 12. Thermal ellipsoids are set at $35 \%$ probability level. Hydrogen atoms and cocrystallized $\mathrm{CH}_{2} \mathrm{Cl}_{2}$ are omitted for clarity. Selected bond lengths $[\AA]]$ and angles $\left[{ }^{\circ}\right]$ are as follows: $\mathrm{C}(1)-\mathrm{N}(1)$ 1.277(11), $\mathrm{C}(1)-\mathrm{N}(2)$ 1.393(11), $\mathrm{C}(2)-\mathrm{N}(2)$ 1.396(11), C(2)-N(3) 1.305(11), Ni(1)-N(1) 1.947(8), Ni(1)-N(3) 1.943(8), N(1)-C(1)-N(2) 122.8(8), C(1)-N(2)-C(2) 126.2(7), $\mathrm{N}(2)-\mathrm{C}(2)-\mathrm{N}(3)$ 121.2(8), $\mathrm{C}(2)-\mathrm{N}(3)-\mathrm{Ni}(1)$ 127.5(6), N(1)-Ni(1)-N(3) 89.3(3), C(1)-N(1)-Ni(1), 127.7(6), N(1)-Ni(1)-Br(1) 102.2(3), $\mathrm{N}(1)-\mathrm{Ni}(1)-\mathrm{Br}(2) 120.9(3)$.

$\mathrm{C}(1)-\mathrm{N}(2)$ and $\mathrm{C}(2)-\mathrm{N}(2)$ bond lengths were 1.277(11) $\AA$, 1.305(11) $\AA, 1.393(11) \AA$ and 1.396(11) $\AA$ respectively, indicating the double and single bond character around the imines and amine nitrogen, respectively.

A series of olefin polymerizations were briefly tested as shown in Table 2. Both catalysts $\mathbf{1 2}$ and $\mathbf{1 3}$ exerted high activity for the ethylene homopolymerization (Table 2, entries 1 and 2). As far as we could ascertain, neither propene homopolymerization nor copolymerization of ethylene with polar monomers by using the catalysts derived from $\mathrm{N}$-aryl-1,3,5-triazapenta-1,4-dienes 1-3 have been reported $[18,19]$. Thus, we tested the polymerization activity of the catalyst $\mathbf{1 2}$ in the copolymerization of ethylene with 5-norbornen-2-ol (NBO) and ethyl acrylate (EtA) (Table 2, entries 3 and 4) and propene homopolymerization (Table 2, entry 5). Although the propene homopolymerization activity of catalyst 12 was moderate, catalyst $\mathbf{1 2}$ exerted a high activity in the copolymerization of ethylene with both polar monomers.

\section{Conclusion}

In summary, sterically crowded diimine ligands $\mathbf{3 b}$ and $\mathbf{3 c}$ were prepared in one step in good yields using a micro-flow technique. One of the advantages of using microreactors is the ease of scale-up. It should be possible to scale-up our developed process by either continuous running or by increasing the number of the microreactors. X-ray crystallographic analysis revealed the detailed structure of ligands $\mathbf{3 b}$ and $\mathbf{3 c}$. Interestingly, $3 \mathbf{c}$ retained an asymmetric structure which ran contrary to a previous report. Unexpectedly, both bond lengths of the two amines $\mathrm{C}(1)-\mathrm{N}(2)$ and $\mathrm{C}(2)-\mathrm{N}(2)$ in both ligands were nearly identical, although $\mathrm{N}=\mathrm{C}-\mathrm{N}-\mathrm{C}=\mathrm{N}$ was not in a common plane. The complexation of $\mathbf{3 b}$ and $\mathbf{3 c}$ with nickel afforded $\mathbf{1 2}$ and $\mathbf{1 3 .}$ $\mathrm{X}$-ray crystallographic analysis of $\mathbf{1 2}$ revealed that all the aryl rings are nearly perpendicular to the chelate plane. The nickel complex 12 exerted a high polymerization activity in both ethylene homopolymerization and the copolymerization of ethylene with polar monomers. The synthesized ligands $\mathbf{3 b}$ and 3c retained as many as five aryl rings, which offered another opportunity to change the steric and electric environment. The developed process should be valuable for the preparation of various 1,2,3,4,5-pentaaryl-1,3,5-triazapenta-1,4-diene ligands and for the creation of novel and useful catalysts.

\section{Experimental \\ General}

NMR spectra were recorded on a JEOL Model ECP-400 (400 $\mathrm{MHz}$ for ${ }^{1} \mathrm{H}, 100 \mathrm{MHz}$ for ${ }^{13} \mathrm{C}$ ) instrument in the indicated solvent. Chemical shifts are reported in units of parts per

Table 2: Evaluation of polymerization activities of nickel complexes 12 and $13 .^{a}$

\begin{tabular}{|c|c|c|c|c|}
\hline entry & catalyst $^{\mathrm{b}}$ & monomer $^{\mathrm{c}}$ & $\begin{array}{c}\text { temperature, time } \\
{\left[{ }^{\circ} \mathrm{C}, \mathrm{h}\right]}\end{array}$ & $\begin{array}{c}V_{\mathrm{p}} \\
{[\mathrm{kg} / \mathrm{mol} \cdot \mathrm{h}]}\end{array}$ \\
\hline 1 & 12 & ethylene & $60,0.5$ & 140 \\
\hline 2 & 13 & ethylene & $60,0.5$ & 110 \\
\hline 3 & 12 & ethylene/NBO & 60,1 & 25 \\
\hline 4 & 12 & ethylene/EtA & 60,1 & 35 \\
\hline 5 & 12 & propene & 60,1 & 5 \\
\hline
\end{tabular}

aEntries 1-4 were carried out in a $2 \mathrm{~L}$ autoclave reactor in $1 \mathrm{~L}$ toluene in the presence of 500 equiv of modified methyl aluminoxane (MMAO)[39] as cocatalyst and 400 psig of ethylene. Entry 5 was carried out in a $2 \mathrm{~L}$ autoclave reactor in $750 \mathrm{~mL}$ propene in the presence of 500 equiv of MMAO as the cocatalyst. ${ }^{b}$ Entries 1,4 and 5 were carried out using $0.11 \mathrm{mmol}$ of the catalyst. Entries 2 and 3 were carried out using 0.10 and 0.09 mmol of the catalysts, respectively. ' Entries 3 and 4 were carried out using 500 equiv of NBO or EtA. 
million (ppm) relative to the signal $(0.00 \mathrm{ppm})$ for internal tetramethylsilane for solutions in $\mathrm{CDCl}_{3}\left(7.26 \mathrm{ppm}\right.$ for ${ }^{1} \mathrm{H}, 77.0$ ppm for $\left.{ }^{13} \mathrm{C}\right)$. Multiplicities are reported by using the following abbreviations: s, singlet; $d$, doublet; $t$, triplet; q, quartet; $m$, multiplet; br, broad; and, $J$, coupling constants in Hertz. IR spectra were recorded on a Perkin-Elmer Spectrum One FTIR spectrometer. HRMS (ESI-TOF) was measured with a Waters LCT Premier ${ }^{\mathrm{TM}}$ XE. All reactions were monitored by thin-layer chromatography carried out on $0.25 \mathrm{~mm}$ E. Merck silica gel plates (60F-254) with UV light, visualized by ceric sulfate solution. Flash column chromatography was performed on Silica Gel $60 \mathrm{~N}$, purchased from Kanto Chemical Co. The T-shape mixer (Flom Co. Ltd., \#9513, $19 \mathrm{~mm} \times 28 \mathrm{~mm} \times 8 \mathrm{~mm}$, diameter $0.6 \mathrm{~mm}$ ) was made of stainless steel and had a T-shape channel. The reaction tube (diameter $0.5 \mathrm{~mm}$ ) was made of Teflon ${ }^{\circledR}$. A Harvard Pump 11 Plus Single Syringe (HARVARD apparatus), a KDS 100 syringe pump, and a KDS 200 syringe pump (KD Scientific) were used to inject compounds into the T-shape mixers. The workup process included quenching of the reactions, liquid-liquid extraction, washing and drying, and was performed using a Zodiac CCX-1200 (Tokyo Rikakikai Co., Ltd.). Chromatographic separation was performed using a Purif $^{\circledR}-\alpha 2$ (Shoko Scientific Co., Ltd.).

\section{Experimental details}

General procedure for the preparation of imidochlorides: The mixture of $N$-(1-naphthyl)benzamide and $\mathrm{SOCl}_{2}(2 \mathrm{~mL} /$ mmol amide) was stirred at $65^{\circ} \mathrm{C}$ for $4 \mathrm{~h}$. The reaction mixture was concentrated in vacuo. The residue was used for the next reaction without further purification.

General procedure for micro-flow synthesis of $1,2,3,4,5-$ pentaaryl-1,3,5-triazapenta-1,4-dienes $3 \mathrm{~b}$ and 3c: A T-shape mixer and reaction tube were immersed in a water bath $\left(20^{\circ} \mathrm{C}\right)$. Syringe pumps and a mixer were connected using a Teflon ${ }^{\circledR}$ tube (diameter $0.25 \mathrm{~mm}$ ). Imidochloride 4 was dried azeotropically with toluene. Aryl amine 5 or $9(0.1 \mathrm{M})$, DIEA $(0.7 \mathrm{M})$ and imidochloride $4(0.1 \mathrm{M})$ were dissolved in $\mathrm{CH}_{2} \mathrm{Cl}_{2}$ under an argon atmosphere and were stored in syringes. Each solution was introduced to a T-shape mixer using the syringe pump. The mixed solution went through the reaction tube, and the resultant solution was poured into vigorously stirred saturated aqueous $\mathrm{NH}_{4} \mathrm{Cl}(1.5 \mathrm{~mL})$ in $\mathrm{CH}_{2} \mathrm{Cl}_{2}(2 \mathrm{~mL})$. After being stirred for several minutes, $\mathrm{Et}_{2} \mathrm{O}(30 \mathrm{~mL})$ was added to the reaction mixture under vigorous stirring for $30 \mathrm{~s}$. The aqueous layer was separated and added to saturated aqueous $\mathrm{NaHCO}_{3}(2 \mathrm{~mL})$ after being vigorously stirred for $30 \mathrm{~s}$. The aqueous layer was separated and brine $(2 \mathrm{~mL})$ was added followed by vigorous stirring for $30 \mathrm{~s}$. After removing the aqueous layer, the organic layers were dried over $\mathrm{Na}_{2} \mathrm{SO}_{4}(10 \mathrm{~g})$ and concentrated in vacuo. The residue was purified by column chromatography on silica gel $\left(0 \%\right.$ to $10 \% \mathrm{Et}_{2} \mathrm{O}$ in hexane with $\left.1 \% \mathrm{Et}_{3} \mathrm{~N}\right)$ to give 1,2,3,4,5-pentaaryl-1,3,5-triazapenta-1,4-diene $\mathbf{3 b}$ or $\mathbf{3 c}$.

1,3,5-Trinaphthyl-2,4-diphenyl-triazapenta-1,4-diene (3b): ${ }^{1} \mathrm{H} \mathrm{NMR}\left(400 \mathrm{MHz}, \mathrm{CDCl}_{3}\right.$ ) $\delta 8.22$ (brd, $\left.J=5.8 \mathrm{~Hz}, 1 \mathrm{H}\right), 8.15$ (brs, 1H), 7.89 (brd, $J=5.4 \mathrm{~Hz}, 1 \mathrm{H}), 7.74-7.90$ (m, 2H), 7.73 (brd, $J=6.8 \mathrm{~Hz}, 2 \mathrm{H}), 7.58$ (brd, $J=7.8 \mathrm{~Hz}, 1 \mathrm{H}), 7.10-7.58(\mathrm{~m}$, 20H), 7.07 (t, $J=7.8 \mathrm{~Hz}, 1 \mathrm{H}), 7.39$ (brd, $J=7.8,1 \mathrm{H}$ ), 6.64 (brs, $1 \mathrm{H}) ;{ }^{13} \mathrm{C} \mathrm{NMR}\left(67.8 \mathrm{MHz}, \mathrm{CDCl}_{3}\right) \delta 156.2,145.6,136.1$, $135.2,134.7,134.0,130.1,129.5,128.8,128.3,128.2,127.2$, $126.3,125.9,125.8,125.6,125.2,125.0,123.6,123.5,123.0$, 122.5, 121.6, 118.0, 115.7; FTIR (neat) 3055, 1624, 1572, 1529, 1495, 1393, 791, $771 \mathrm{~cm}^{-1}$; HRMS (ESI-TOF, $\mathrm{m} / z$ ): [M $+\mathrm{H}]^{+}$calcd. for $\mathrm{C}_{44} \mathrm{H}_{32} \mathrm{~N}_{3}, 602.2596$; found, 602.2613 .

1,3-Dinaphthyl-2,4,5-triphenyl-triazapenta-1,4-diene (3c): ${ }^{1} \mathrm{H}$ NMR (400 MHz, $\left.\mathrm{CDCl}_{3}\right) \delta 8.29(\mathrm{~d}, J=6.4 \mathrm{~Hz}, 2 \mathrm{H}), 8.25(\mathrm{~d}$, $J=8.3 \mathrm{~Hz}, 2 \mathrm{H}), 7.78(\mathrm{brd}, J=7.8 \mathrm{~Hz}, 1 \mathrm{H}), 7.73(\mathrm{~d}, J=7.8 \mathrm{~Hz}$, $2 \mathrm{H}), 7.61(\mathrm{~d}, J=7.8 \mathrm{~Hz}, 1 \mathrm{H}), 7.36-7.60(\mathrm{~m}, 9 \mathrm{H}), 7.40-7.20(\mathrm{~m}$, $2 \mathrm{H}), 7.16(\mathrm{t}, J=7.8 \mathrm{~Hz}, 1 \mathrm{H}), 7.05-6.60(\mathrm{~m}, 7 \mathrm{H}), 6.54$ (brs, $1 \mathrm{H})$, 5.71 (brd, $J=6.8,1 \mathrm{H}$ ); FTIR (neat) 3056, 1631, 1595, 1524, 1497, 1438, 1323, 775, $698 \mathrm{~cm}^{-1}$; HRMS (ESI-TOF, $\mathrm{m} / z$ ): [M $+\mathrm{H}]^{+}$calcd. for $\mathrm{C}_{40} \mathrm{H}_{30} \mathrm{~N}_{3}$, 552.2440; found, 552.2435.

\section{General procedure for the preparation of nickel complexes 12 and 13}

The following manipulations were performed under an inert atmosphere using standard glove box techniques. A solution of the prepared ligand $\mathbf{3 b}$ or $\mathbf{3 c}$ ( 1 equiv) and $\mathrm{NiBr}_{2}(\mathrm{dme})$ (1 equiv) in dry $\mathrm{CH}_{2} \mathrm{Cl}_{2}(50 \mathrm{~mL} / \mathrm{mmol})$ was stirred for $4 \mathrm{~h}$ at room temperature. The obtained crude mixture was used for the polymerization without purification.

\section{Procedure for the preparation of nickel complex 12 crystals}

The following manipulations were performed under an inert atmosphere using standard glove box techniques. A solution of the prepared ligand $\mathbf{3 b}(66 \mathrm{mg}, 0.11 \mathrm{mmol})$ in $40 \mathrm{~mL}$ of dry $\mathrm{CH}_{2} \mathrm{Cl}_{2}$ was slowly added to $\mathrm{NiBr}_{2}(\mathrm{dme})(34 \mathrm{mg}, 0.11 \mathrm{mmol})$. The resultant mixture was stirred for $1 \mathrm{~h}$ at room temperature. Then, the stirring was stopped and the mixture was allowed to stand overnight at room temperature. Green colored needle-like crystals of 12, suitable for X-ray analysis were obtained.

\section{Procedure for the homopolymerization of ethylene}

To a $2 \mathrm{~L}$ autoclave reactor, $1,000 \mathrm{~mL}$ of dry toluene and MMAO (500 equiv, $6.5 \mathrm{wt} \%$ in toluene) were added. The resultant mixture was heated to $60{ }^{\circ} \mathrm{C}$, then the crude nickel complex ( 1 equiv) was injected under an ethylene pressure of 400 psig, which was fed continuously at that pressure over the course of the reaction. After being stirred for $0.5 \mathrm{~h}$, ethanol was 
added to quench the polymerization, and ethylene was vented. The resultant mixture was collected, and concentrated in vacuo to afford a crude polymer. Polymerization activities were calculated from the mass of the crude polymer that was obtained.

\section{Procedure for the copolymerization of ethylene with polar monomers}

To a $2 \mathrm{~L}$ autoclave reactor, $1,000 \mathrm{~mL}$ of dry toluene and comonomers (500 equiv) along with MMAO (500 equiv, $6.5 \mathrm{wt} \%$ in toluene) were added. The resultant mixture was heated to $60{ }^{\circ} \mathrm{C}$, then the crude nickel complex (1 equiv) was injected under an ethylene pressure of 400 psig, which was fed continuously at that pressure over the course of the reaction. After being stirred for $1 \mathrm{~h}$, ethanol was added to quench the polymerization, and ethylene was vented. The resultant mixture was collected, and concentrated in vacuo to afford the crude polymer. Polymerization activities were calculated from the mass of the crude polymer that was obtained.

\section{Procedure for the homopolymerization of propene}

To a $2 \mathrm{~L}$ autoclave reactor, MMAO (500 equiv, $6.5 \mathrm{wt} \%$ in toluene) and $750 \mathrm{~mL}$ of propene were added. Then the crude nickel complex (1 equiv) was injected with nitrogen. The resultant mixture was heated to $60{ }^{\circ} \mathrm{C}$. After being stirred for $1 \mathrm{~h}$, ethanol was added to quench the polymerization, and propene was vented. The resultant mixture was collected, and concentrated in vacuo to afford a crude polymer. Polymerization activities were calculated from the mass of the crude polymer that was obtained.

\section{Supporting Information}

\section{Supporting Information File 1 \\ ${ }^{1} \mathrm{H}$ and ${ }^{13} \mathrm{C}$ NMR spectra. \\ [http://www.beilstein-journals.org/bjoc/content/ \\ supplementary/1860-5397-9-268-S1.pdf]}

\section{Acknowledgements}

The authors thank Dr. Hidehiro Uekusa, Tokyo Institute of Technology for X-ray crystallographic analysis of intermediates and Dr. Shigekazu Ito, Tokyo Institute of Technology for fruitful discussion, and Global COE Program "Education and Research Center for Emergence of New Molecular Chemistry," MEXT, Japan, for financial support.

\section{References}

1. Ittel, S. D.; Johnson, L. K.; Brookhart, M. Chem. Rev. 2000, 100, 1169. doi:10.1021/cr9804644

2. Lersch, M.; Tilset, M. Chem. Rev. 2005, 105, 2471.

doi:10.1021/cr030710y
3. Dagorne, S.; Atwood, D. A. Chem. Rev. 2008, 108, 4037. doi:10.1021/cr078351k

4. Nakamura, A.; Ito, S.; Nozaki, K. Chem. Rev. 2009, 109, 5215. doi:10.1021/cr900079r

5. Chen, E. Y.-X. Chem. Rev. 2009, 109, 5157. doi:10.1021/cr9000258

6. Mkhalid, I. A. I.; Barnard, J. H.; Marder, T. B.; Murphy, J. M.; Hartwig, J. F. Chem. Rev. 2009, 110, 890. doi:10.1021/cr900206p

7. Driver, T. G. Org. Biomol. Chem. 2010, 8, 3831. doi:10.1039/c005219c

8. Xu, L.-M.; Li, B.-J.; Yang, Z.; Shi, Z.-J. Chem. Soc. Rev. 2010, 39, 712. doi:10.1039/B809912J

9. Asay, M.; Jones, C.; Driess, M. Chem. Rev. 2010, 111, 354. doi:10.1021/cr100216y

10. Nomura, K.; Zhang, S. Chem. Rev. 2010, 111, 2342. doi:10.1021/cr100207h

11. Sehnal, P.; Taylor, R. J. K.; Fairlamb, I. J. S. Chem. Rev. 2010, 110, 824. doi: $10.1021 / \mathrm{cr} 9003242$

12. Delferro, M.; Marks, T. J. Chem. Rev. 2011, 111, 2450. doi:10.1021/cr1003634

13. Partyka, D. V. Chem. Rev. 2011, 111, 1529. doi:10.1021/cr1002276

14. Takeuchi, D. Macromol. Chem. Phys. 2011, 212, 1545. doi:10.1002/macp.201100182

15. Gephart, R. T., III; Warren, T. H. Organometallics 2012, 31, 7728. doi:10.1021/om300840z

16. Lang, H.; Jakob, A.; Milde, B. Organometallics 2012, 31, 7661. doi:10.1021/om300628g

17. Li, T.; Schulz, S.; Roesky, P. W. Chem. Soc. Rev. 2012, 41, 3759. doi:10.1039/c2cs15343b

18. Valdebenito, C.; Garland, M. T.; Quijada, R.; Rojas, R. J. Organomet. Chem. 2009, 694, 717. doi:10.1016/j.jorganchem.2008.11.066

19. Peoples, B. C.; De la Vega, G.; Valdebenito, C.; Quijada, R.; Ibañez, A.; Valderrama, M.; Rojas, R. J. Organomet. Chem. 2012, 700 147. doi:10.1016/j.jorganchem.2011.11.035

20. Masuda, J. D.; Stephan, D. W. Can. J. Chem. 2005, 83, 477. doi:10.1139/v05-057

21. Masuda, J. D.; Stephan, D. W. Dalton Trans. 2006, 2089. doi:10.1039/B513531A

22. Cotton, F. A.; Daniels, L. M.; Matonic, J. H.; Wang, X. P.; Murillo, C. A. Polyhedron 1997, 16, 1177. doi:10.1016/s0277-5387(96)00366-x

23. Fuse, S.; Masui, H.; Tannna, A.; Shimizu, F.; Takahashi, T. ACS Comb. Sci. 2012, 14, 17. doi:10.1021/co200081j

24. Masui, H.; Fuse, S.; Takahashi, T. Org. Lett. 2012, 14, 4090 doi:10.1021/ol3017337

25. Cooper, F. C.; Partridge, M. W.; Short, W. F. J. Chem. Soc. 1951, 391. doi:10.1039/jr9510000391

26. Tanaka, K.; Motomatsu, S.; Koyama, K.; Tanaka, S.-i.; Fukase, K. Org. Lett. 2006, 9, 299. doi:10.1021/ol062777o

27. Nagaki, A.; Togai, M.; Suga, S.; Aoki, N.; Mae, K.; Yoshida, J.-i. J. Am. Chem. Soc. 2005, 127, 11666. doi:10.1021/ja0527424

28. Luis, S. V.; Carcia-Verdugo, E., Eds. Chemical Reactions and Processes under Flow Conditions; Royal Society of Chemistry: Cambridge, 2010. doi:10.1039/9781847559739

29. McMullen, J. P.; Jensen, K. F. Annu. Rev. Anal. Chem. 2010, 3, 19. doi:10.1146/annurev.anchem.111808.073718

30. Fuse, S.; Tanabe, N.; Yoshida, M.; Yoshida, H.; Doi, T.; Takahashi, T. Chem. Commun. 2010, 46, 8722. doi:10.1039/c0cc02239j

31. Suga, S.; Yamada, D.; Yoshida, J. Chem. Lett. 2010, 39, 404. doi:10.1246/cl.2010.404

32. Baumann, M.; Baxendale, I. R.; Ley, S. V. Mol. Diversity 2011, 15, 613. doi:10.1007/s11030-010-9282-1 
33. Yoshida, J.-i.; Kim, H.; Nagaki, A. ChemSusChem 2011, 4, 331. doi:10.1002/cssc.201000271

34. Fuse, S.; Tanabe, N.; Takahashi, T. Chem. Commun. 2011, 47, 12661. doi:10.1039/c1cc15662d

35. Fuse, S.; Mifune, Y.; Tanabe, N.; Takahashi, T. Org. Biomol. Chem. 2012, 10, 5205. doi:10.1039/c2ob25511a

36. CCDC 934692 (3b), CCDC 934694 (3c), and 934693 (12) contain the supplementary crystallographic data for this paper. These data can be obtained free of charge from The Cambridge Crystallographic Data Centre via http://www.ccdc.cam.ac.uk/data_request/cif.

37. Caris, R.; Peoples, B. C.; Valderrama, M.; Wu, G.; Rojas, R. J. Organomet. Chem. 2009, 694, 1795. doi:10.1016/j.jorganchem.2009.01.005

38. Azoulay, J. D.; Rojas, R. S.; Serrano, A. V.; Ohtaki, H.; Galland, G. B.; Wu, G.; Bazan, G. C. Angew. Chem., Int. Ed. 2009, 48, 1089. doi:10.1002/anie.200804661

39. MMAO is a modified methylaluminoxane activator containing $25 \%$ isobutyl aluminoxane prepared by the controlled hydrolysis of $\mathrm{Me}_{3} \mathrm{Al}$ and $(\mathrm{iBu})_{3} \mathrm{Al}$.

\section{License and Terms}

This is an Open Access article under the terms of the Creative Commons Attribution License

(http://creativecommons.org/licenses/by/2.0), which permits unrestricted use, distribution, and reproduction in any medium, provided the original work is properly cited.

The license is subject to the Beilstein Journal of Organic Chemistry terms and conditions:

(http://www.beilstein-journals.org/bjoc)

The definitive version of this article is the electronic one which can be found at: doi:10.3762/bjoc. 9.268 